\title{
Yersinia pestis Ail: multiple roles of a single protein
}

\section{Anna M. Kolodziejek*, Carolyn J. Hovde and Scott A. Minnich}

School of Food Science, University of Idaho, Moscow, ID, USA

Edited by:

Matthew Francis, Umeå University,

Sweden

Reviewed by:

Eric Krukonis, University of

Michigan, USA

Mikael Skurnik, University of

Helsinki, Finland

*Correspondence:

Anna M. Kolodziejek, School of Food

Science, University of Idaho,

Moscow, ID 83844-2311, USA.

e-mail:akolodziejek@

vandals. uidaho.edu
Yersinia pestis is one of the most virulent bacteria identified. It is the causative agent of plague-a systemic disease that has claimed millions of human lives throughout history. $Y$. pestis survival in insect and mammalian host species requires fine-tuning to sense and respond to varying environmental cues. Multiple $Y$. pestis attributes participate in this process and contribute to its pathogenicity and highly efficient transmission between hosts. These include factors inherited from its enteric predecessors; Y. enterocolitica and $Y$. pseudotuberculosis, as well as phenotypes acquired or lost during $Y$. pestis speciation. Representatives of a large Enterobacteriaceae Ail/OmpX/PagC/Lom family of outer membrane proteins (OMPs) are found in the genomes of all pathogenic Yersiniae. This review describes the current knowledge regarding the role of Ail in Y. pestis pathogenesis and virulence. The pronounced role of Ail in the following areas are discussed (1) inhibition of the bactericidal properties of complement, (2) attachment and Yersinia outer proteins (Yop) delivery to host tissue, (3) prevention of PMNL recruitment to the lymph nodes, and (4) inhibition of the inflammatory response. Finally, Ail homologs in $Y$. enterocolitica and $Y$. pseudotuberculosis are compared to illustrate differences that may have contributed to the drastic bacterial lifestyle change that shifted $Y$. pestis from an enteric to a vector-born systemic pathogen.

Keywords: Yersinia pestis, Ail, OmpX, serum resistance, virulence, adhesion, invasion, T3SS

\section{Yersinia pestis-BRIEF CHARACTERISTICS OF A MOST NOTORIOUS PATHOGEN}

$Y$. pestis is a Gram negative, non-motile, facultative anaerobic rod that exhibits bipolar staining (classic safety-pin pattern). It is a zoonotic pathogen and the causative agent of plague-a systemic disease that has claimed millions of human lives throughout history. The infectious dose is extremely low, estimated between 1 and 10 organisms, making it one of the most virulent bacteria identified (Perry and Fetherston, 1997). In its sylvatic cycle, Y. pestis moves between fleas (the arthropod vector) and rodents (reservoir host) with transmission occurring when the vector takes a blood meal. A state of high bacteremia in the mammalian host at the time of the bite is required for a flea infection. Rarely, the disease can be spread through direct contact between infected animals (Wimsatt and Biggins, 2009). Flea-borne Y. pestis infection in humans leads to the development of bubonic and septicemic plague that can progress to secondary pneumonic plague (Perry and Fetherston, 1997; Sebbane et al., 2006). This airborne form of the disease can be transmitted directly between humans without the vector involvement, causing primary pneumonic disease. Human-to-human airborne infection is of special importance because of the rapid spread and progression of the disease (short incubation period up to 2-3 days), and very high mortality rates (approaching 100\% if untreated) (Perry and Fetherston, 1997). The characteristics of pneumonic plague highlight the sobering potential for Y. pestis employment as a biological warfare agent.

Phylogenetic analyses indicate $Y$. pestis evolved relatively recently (within the last 20,000 years) from Yersinia pseudotuberculosis, an enteropathogen that causes self-limiting infections (Achtman et al., 1999, 2004; Skurnik et al., 2000). Even though the bacterial genomes shares $>90 \%$ similarity, the disease transmission, course of the infection, morbidity, and mortality are dramatically different (Bercovier et al., 1980; Eppinger et al., 2007). One of the reasons $Y$. pestis is so efficient is tight expression control of specific genes in response to the host environment. Characteristic host cycling of $Y$. pestis is reflected in global genetic responses in which temperature and calcium ions are key environmental cues the organism senses (Perry and Fetherston, 1997). This is facilitated by virulence phenotypes common with Y. pseudotuberculosis and Y. enterocolitica, as well as the acquisition of new determinants due to genetic acquisition and genomic entropy (Ben-Gurion and Shafferman, 1981; Perry and Fetherston, 1997; Parkhill et al., 2001; Moran, 2002; Anisimov et al., 2004; Chain et al., 2004, 2006; Darby et al., 2005; Erickson et al., 2006, 2008; Montminy et al., 2006; Sebbane et al., 2006, 2009; Derbise et al., 2007; Lathem et al., 2007; Hinnebusch and Erickson, 2008; Sun et al., 2008).

The Ail/OmpX/PagC/Lom family is a family of outer membrane proteins (OMPs) found in organisms like Y. enterocolitica (Ail), Y. pseudotuberculosis (Ail), Salmonella enterica serovar typhimurium (Rck, PagC), or Escherichia coli (OmpX). Particular members of the family are responsible for conferring resistance to complement-mediated killing, survival in macrophages, and adhesion and invasion of host cells (Miller et al., 1989a; Bliska and Falkow, 1992; Heffernan et al., 1992; Cirillo et al., 1996). Y. pestis Ail protein (also known as OmpX) has been found to be an important virulence factor during plague pathogenesis 
(Kolodziejek et al., 2010; Hinnebusch et al., 2011). Although our laboratory first designated this protein as OmpX, accordingly to the annotations in the $Y$. pesis KIM genome, due to the subsequent and common use by others of the designation "Ail" we refer to the protein as Ail, rather than OmpX, in this review.

The prominent role of Ail in serum resistance (Kolodziejek et al., 2007, 2010; Bartra et al., 2008), adhesion to and internalization into host cells (Kolodziejek et al., 2007, 2010; Felek and Krukonis, 2009; Tsang et al., 2010), Yersinia outer proteins (Yop) delivery (Felek and Krukonis, 2009; Tsang et al., 2010; Yamashita et al., 2011), and inhibition of inflammatory response has been shown (Felek and Krukonis, 2009; Hinnebusch et al., 2011).

This review is a compendium of the current knowledge of the roles of Ail in $Y$. pestis pathogenesis and virulence. Similarities between Ail from Y. enterocolitica and Y. pseudotuberculosis are shown to illustrate functional similarity and differences between the proteins. The characteristics of the $Y$. pestis strains used in the studies described below are included in Table 1 to help the reader follow the rational for particular strain use.

\section{PRIMARY, SECONDARY, AND TERTIARY STRUCTURE OF AIL}

The genome of $Y$. pestis KIM encodes four homologs of the Ail protein: $y 1324, y 1682, y 2034$, and $y 2446$ (designated YPO2905, YPO2506, YPO2190, YPO1860, accordingly in Y. pestis CO92 genome), which are also present in $Y$. pseudotuberculosis genome. The gene designated $y 1324$ encodes a protein with a predicted molecular mass of $17.47 \mathrm{kDa}$ (without the signal sequence) and shares the highest amino acid sequence similarity to an Ail protein from Y. enterocolitica ( 70\%) (Kolodziejek et al., 2007; Bartra et al., 2008) (Figure 1).

Analysis of the ail nucleotide sequence reveals differences among the $Y$. pestis isolates that result in amino acid variation in the polypeptide chain (Eroshenko et al., 2010). Two variable sites in the gene can be identified: (1) a missense mutation in position 376 that results in a codon change from GTT to TTT and consequently a substitution of Val126 (Y. pestis Pestoides F, Angola, Y. pestis subsp. caucasica, altaica, hissarica) to Phe (Y.pestis KIM, CO92, Antiqua, Nepal 516, Y. pestis subsp. ulegeica) (2) insertion of an AGT triplet at position 406 that results in the addition of an extra Ser137 in the Ail polypeptide chain (Y. pestis Pestoides F, Y. pestis subsp. caucasica) (Figure 1).

Bioinformatic analysis of the $y 1324$ gene also reveals two potential products differing in the length of the signal sequence peptide (predicted 38 and 26-residues long). The exact translational start sites have not been confirmed, but due to the lack of a clear ribosomal binding site and less preferable GTG codon start for the 38-residue long signal sequence peptide, the translational start resulting in the shorter signal sequence is preferable. The signal peptide cleavage site is located between Ala and Glu and has been identified by both bioinformatic and peptide ion mapping analysis (Kolodziejek et al., 2007) (Figure 1).

Ail is a small, monomeric, surface-associated protein localized in the OM (Pieper et al., 2009a). The crystal structure of Yersinia pestis Ail is available (Figure 2). It reveals that Ail forms an eight-stranded antiparallel $\beta$-barrel with four extracellular loops (Figure 2). The amino acid similarity to the members of the Ail/Lom/OmpX family is the highest for the transmembrane regions with little sequence conservation in the extracellular loops (Bartra et al., 2008; Yamashita et al., 2011). No obvious channel through the barrel in the tertiary model can be found (Yamashita et al., 2011). A hydrophobic cleft and two regions with positive charge found on the extracellular surface are indicated to participate in Ail-conferred adhesion to substrates (Yamashita et al., 2011). The NMR and CD (circular dichroism) structural studies also confirm that Ail adopts a transmembrane $\beta$-barrel in micells and lipid bilayers (Plesniak et al., 2011).

Table 1 | Characteristics and virulence of selected $Y$. pestis strains used in laboratory studies.

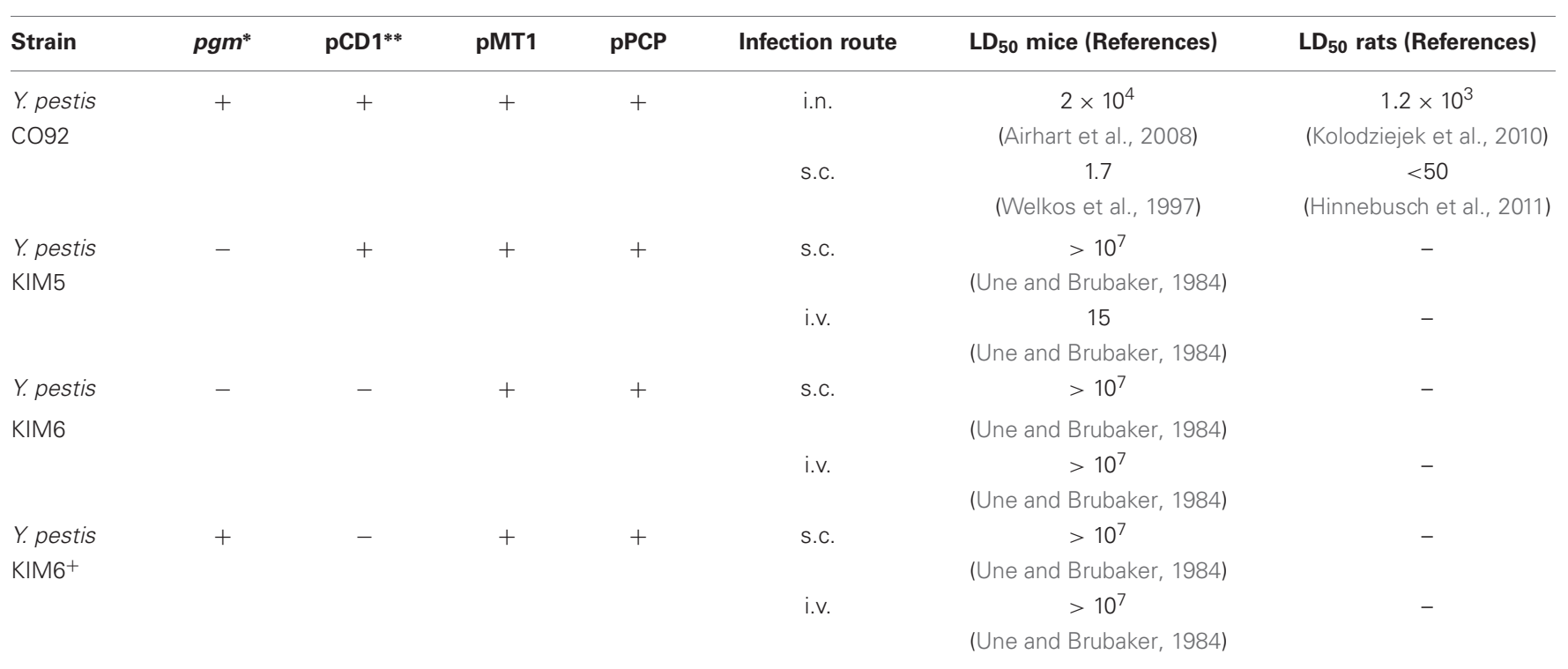

*, biofilm-related loci; **, encodes Type Three Secretory System (T3SS). i.n., intranasal; s.c., subcutaneous; i.v., intravenous. 


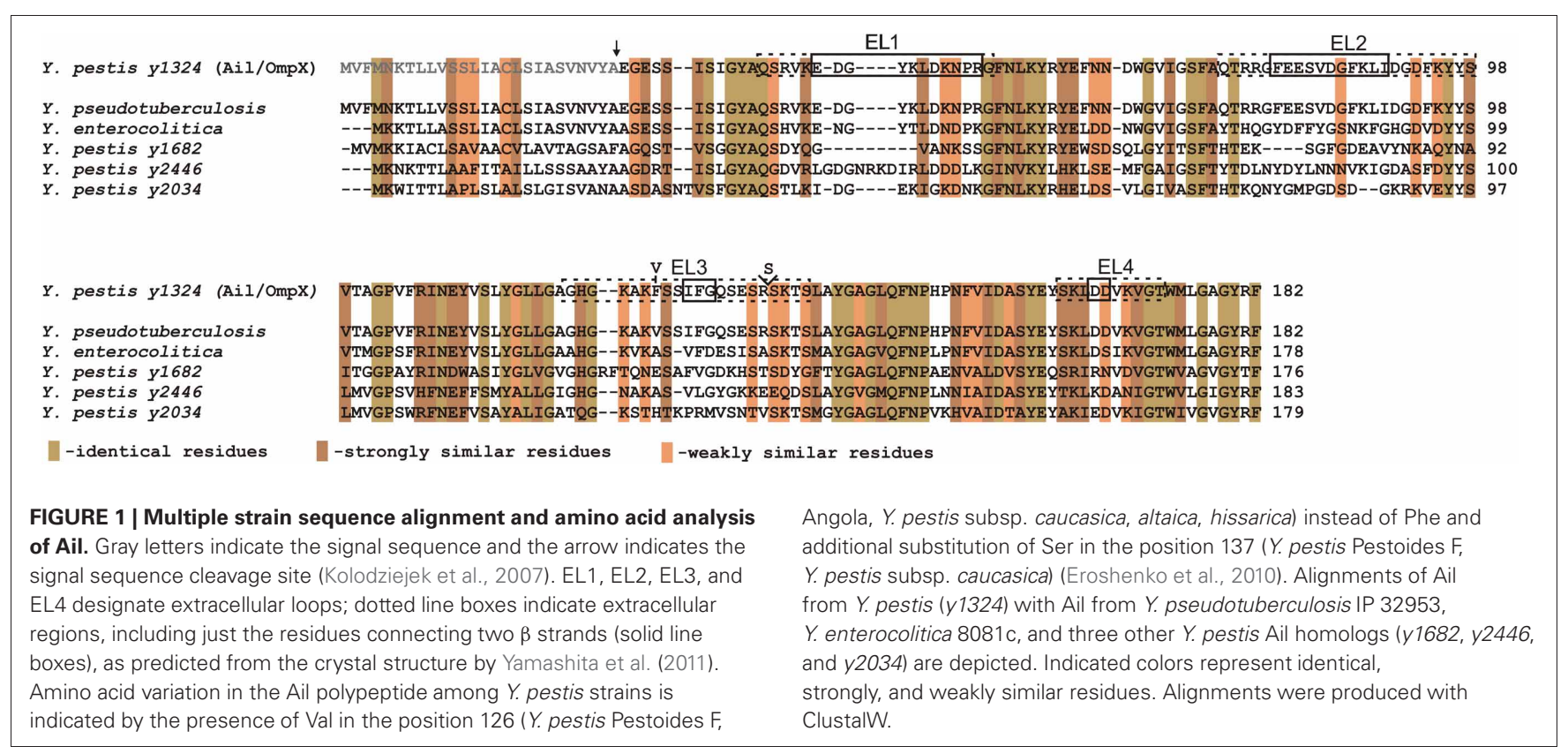

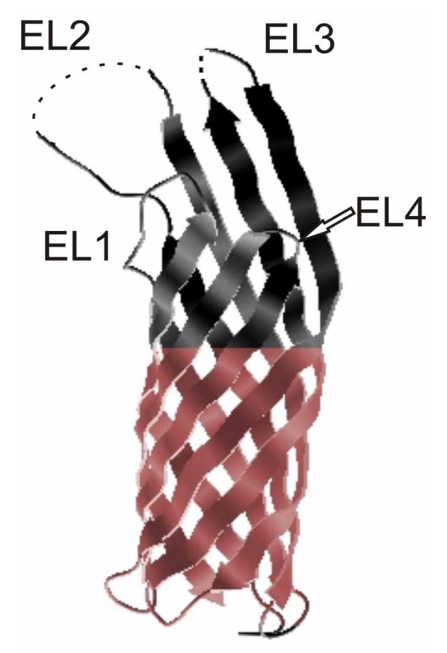

FIGURE 2 | Crystal structure of Ail. Extracellular loops are indicated EL1, $E L 2, E L 3$, and EL4 and the hydrophobic belt is indicated in color. The tips of EL2 and EL3 are disordered and these regions are marked with dotted lines (Yamashita et al., 2011). The figure was generated from the PDBe Protein Data Bank in Europe.

\section{REGULATION OF AIL EXPRESSION}

Ail is the most highly transcribed gene in the entire Y. pestis transcriptome (Chauvaux et al., 2007, 2011) and the protein encompasses $\sim 20-30 \%$ of the total OM proteome when the bacterium is grown at $37^{\circ} \mathrm{C}$, the optimal temperature for Ail expression (Myers-Morales et al., 2007; Pieper et al., 2009a,b). The protein is still abundant, but expressed at lower levels at ambient temperature $\left(28^{\circ} \mathrm{C}\right)$ (Kolodziejek et al., 2007; Bartra et al., 2008; Pieper et al., 2009a,b) and the expression is minimal at $6^{\circ} \mathrm{C}$ (Bartra et al., 2008). The label-free comparative proteome strategy used to identify new virulence targets reveals that Ail clusters together with plasmid pCD1 virulence-associated proteins; the protein displays a similar pattern of expression and abundance shown for YopD, a secreted effector protein that is part of the type three secretion system (T3SS) (Hixson et al., 2006). Transcription of Ail can be also altered due to the mutagenesis of other OM components. Studies show that Ail is down-regulated at $26^{\circ} \mathrm{C}$, but not at $37^{\circ} \mathrm{C}$, when Braun lipoprotein is deleted (Galindo et al., 2010).

Significant presence of Ail in Y. pestis OM at ambient temperature is in contrast to Ail expression in Y. enterocolitica in which the protein is expressed at very low levels at this temperature (Bliska and Falkow, 1992; Pierson and Falkow, 1993). Additionally, the overall comparison of the ail transcriptional pattern in $Y$. pestis and $Y$. pseudotuberculosis reveals that the expression of ail in $Y$. pestis is at a much higher level than in Y. pseudotuberculosis (Chauvaux et al., 2011). This implies that the two organism, despite the almost identical gene sequence, use the Ail in a different manner depending on the physiological requirements and this could potentially explain some differences in pathogenicity between the two (Chauvaux et al., 2011).

\section{AIL CONFERS SERUM RESISTANCE IN $Y$. pestis}

Complement-dependent bacterial killing is one of the first lines of innate immunity against pathogens (Tedesco, 2008). Thus, resistance to serum complement is an essential phenotype for bacterial survival in blood. Y. pestis transmission between insect and mammalian species is determined by continual contact of the bacteria with blood components (Perry and Fetherston, 1997). $Y$. pestis can resist the bactericidal effects of serum when it is grown at $26^{\circ} \mathrm{C}$ and $37^{\circ} \mathrm{C}$, but not at $6^{\circ} \mathrm{C}$ (Anisimov et al., 2005). These temperatures correlate with ambient, mammalian core body, and insect hibernation conditions, respectively (Anisimov et al., 2005); and complement resistance reflects Ail expression 
pattern (Bartra et al., 2008). Out of four Ail/OmpX homologs encoded in the $Y$. pestis genome, only y1324 confers resistance to human serum. Deletion of this gene results in a rapid, essentially $100 \%$ loss of serum resistance (Kolodziejek et al., 2007; Bartra et al., 2008). This loss is attributed to the action of complement because heat-inactivated serum does not have lethal properties (Kolodziejek et al., 2007; Bartra et al., 2008). Additionally, the ail gene confers resistance to complement killing by rat, goat, sheep, rabbit, and guinea pig sera (Bartra et al., 2008; Kolodziejek et al., 2010). Interestingly, complement-killing of the Ail deletion mutant is not observed when the bacteria are incubated with mouse sera (Bartra et al., 2008; Kolodziejek et al., 2010); phenomenon observed with a number of common microorganisms that can be killed by sera of other species, but remain resistant to murine sera (Marcus et al., 1954; Kolodziejek et al., 2010). The limited bactericidal activity of murine sera remains unclear.

Ail expressed in a bacterial host other than Y. pestis (e.g., E. coli) confers serum resistance independently from other $Y$. pestis proteins or LPS (Bartra et al., 2008; Kolodziejek et al., 2010).
However, serum resistance does depend on the LPS core structure of the organism in which Ail is being expressed (Figure 3). This can be inferred from indirect and direct evidence. The indirect evidence comes from the observation that $Y$. pestis strains that have shortened LPS core, through directed mutagenesis or as a results of spontaneous mutations, have altered sensitivity to human serum (Anisimov et al., 2005; Knirel et al., 2006, 2007; Dentovskaya et al., 2011) (Figure 3B). Y. pestis full-length LPS inner core, composed of six residues, is required for resistance to human complement, while the outer core monosaccharides do not play a critical role (Dentovskaya et al., 2011). The direct evidence is from the study employing a series of isogenic Ail-expressing E. coli mutants each with progressively truncated LPS (Figure 3C). Both the inner and outer core are required for effective resistance to the bactericidal effect of complement in E. coli as only Ail-expressing E. coli with the full core length are resistance to complement (Kolodziejek et al., 2010).

The observed amino acid variation in the Ail polypeptide chain between different $Y$. pestis isolates (see "Primary, secondary,

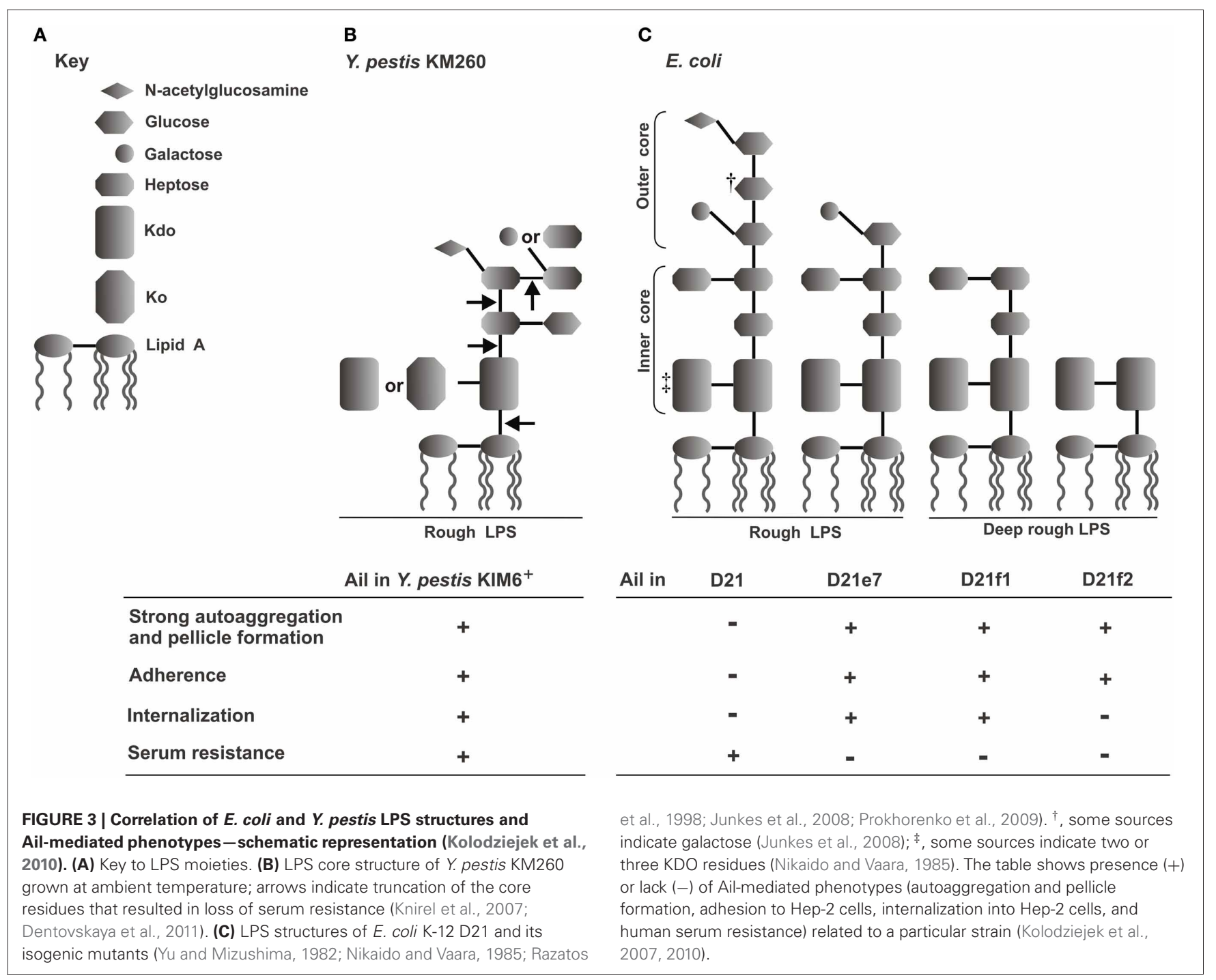


and tertiary structure of Ail" section) seems to be insignificant for the mediation of serum resistance, as all strains were similarly resistant to normal rabbit serum (Eroshenko et al., 2010).

The protection of $Y$. pestis by Ail at either 28 or $37^{\circ} \mathrm{C}$ contrasts with $Y$. enterocolitica Ail, which confers this trait only at $37^{\circ} \mathrm{C}$, reflecting temperature regulation of Ail expression in that organism (Bliska and Falkow, 1992; Pierson and Falkow, 1993). It has been shown that Ail in Y. pseudotuberculosis also confers serum resistance when bacteria are grown at $37^{\circ} \mathrm{C}$ (Yang et al., 1996). In Y. enterocolitica and Y. pseudotuberculosis three factors contribute to serum resistance: Ail, YadA, and O-chain in LPS (Wachter and Brade, 1989; Bliska and Falkow, 1992; Pierson and Falkow, 1993; Yang et al., 1996; Biedzka-Sarek et al., 2005; Heise and Dersch, 2006). Y. pestis does not express YadA or O-chain due to mutations inactivating both the yadA and several genes in the O-chain biosynthetic gene cluster (Rosqvist et al., 1988; Skurnik et al., 2000; Prior et al., 2001); thus they cannot play any role in $Y$. pestis serum resistance. Hence, acquisition of Ailmediated serum resistance at lower temperatures might have been a necessity for the passage of bacteria between mammalian and flea hosts. Although no studies on the mechanisms of serum resistance conferred by $Y$. pestis Ail have been published yet, based on the literature on Ail from Y. enterocolitica and Y. pseudotuberculosis it is plausible that the protein binds negative regulators of alternative (factor $\mathrm{H}$ ), and classical and lectin [C4b-binding protein (C4BP)] complement pathways thus preventing complement attack (Biedzka-Sarek et al., 2008a,b; Kirjavainen et al., 2008; Ho et al., 2012).

\section{ROLE OF AIL IN Y. pestis ADHESION TO MAMMALIAN CELLS}

Adherence to host tissues is an important infection-determining factor used by many bacterial pathogens (Reid and Sobel, 1987). The most favorable conditions for $Y$. pestis adherence to host cells in vitro is pre-incubation of bacteria at $\leq 28^{\circ} \mathrm{C}$ in neutral pH (Felek et al., 2010). Of three major adhesins found among the enteropathogenic Yersiniae, two, YadA and Invasin, are not produced by Y. pestis due to pseudogenes (Rosqvist et al., 1988; Simonet et al., 1996; Forman et al., 2008). PsaA (pH 6 antigen) (Yang et al., 1996; Liu et al., 2006; Felek et al., 2010) and YapE (Lawrenz et al., 2009) are common for Y. pseudotuberculosis and $Y$. pestis, have adhesive properties, and their role in adherence was shown in Y. pseudotuberculosis (PsaA) and Y. pestis (PsaA and YapE). However, a series of studies now show that the primary adhesin in $Y$. pestis is Ail. Deletion of Ail greatly reduces binding of the bacterium to epithelial (HEp-2) and monocytic (THP-1) cells (Kolodziejek et al., 2007; Felek and Krukonis, 2009). Moreover, Ail-expressing E. coli facilitates binding to both cell lines, independent from other $Y$. pestis components (Felek and Krukonis, 2009; Kolodziejek et al., 2010); but, similarly to serum resistance, this phenotype depends on the LPS background in which Ail is expressed (Kolodziejek et al., 2010) (Figure 3C). Recent findings indicate that the 3rd extracellular loop of Ail is important for Ail-mediated binding to host cells (Tsang et al., 2012). Ail-conferred adhesiveness correlates with the bacterial autoaggregation, another phenotype mediated by the protein (see section "Ail and autoaggregation of Y. pestis" below) (Kolodziejek et al., 2007, 2010).
Most importantly, binding of $Y$. pestis to host cells via Ail, promotes Yop delivery into the primary target of T3SS - the phagocytic cells, as well as into epithelial cells (Felek and Krukonis, 2009; Yamashita et al., 2011). Pretreatment of host cells (HEp-2) with anti-Ail serum and deletion of Ail in Y. pestis KIM5 impair Yop delivery, a step critical for Y. pestis pathogenesis (Felek and Krukonis, 2009; Yamashita et al., 2011). The significant delay in Yop delivery by an ail-negative mutant is observed in both cell lines (HEp-2 and THP-1), particularly obvious after the first $2 \mathrm{~h}$ of infection. Around $90 \%$ of Y. pestis KIM5-infected cells indicate cytotoxic characteristic due to the delivery of Yops vs. only $5-10 \%$ of the cells infected with the ail-negative strain. However, after $8 \mathrm{~h}$ of the infection this difference diminishes to only $\sim 15 \%$, which indicates that ail-negative strain is not completely devoid of Yop delivery capabilities (Felek and Krukonis, 2009).

Noteworthy, Y. pestis Ail shares functional homology in adherence with Ail in Y. enterocolitica, but not with the Ail homolog of Y. pseudotuberculosis (Bliska and Falkow, 1992; Yang et al., 1996). Functional discrepancies between Ail from Y. pestis and Y. pseudotuberculosis call for further investigation to establish that several amino acid substitutions can lead to the dramatic change in function and if other species-specific factors, like LPS, influence the functional differences. In contrast to Y. enterocolitica Ail that confers adhesion when bacteria are grown at $37^{\circ} \mathrm{C}$ (Bliska and Falkow, 1992), Ail in Y. pestis can confer this phenotype when grown at both 28 and $37^{\circ} \mathrm{C}$ (Kolodziejek et al., 2007; Felek et al., 2010).

\section{AIL INTERACTIONS WITH THE COMPONENTS OF EXTRACELLULAR MATRIX (ECM)}

Ail-mediated binding of $Y$. pestis or E. coli to the regions between the host cells during in vitro cell culturing indicates that the protein also interacts with the components of the ECM (Kolodziejek et al., 2007; Felek and Krukonis, 2009; Tsang et al., 2010; Yamashita et al., 2011). Purified Ail and Ail-expressing E. coli bind specifically to laminin, fibronectin, negatively charged HSPGs, but not collagen I or IV (Tsang et al., 2010; Yamashita et al., 2011). In vitro models employing human cell lines and $Y$. pestis show that the bacterium binds to fibronectin and laminin via Ail (Tsang et al., 2010; Yamashita et al., 2011); however, Ail is not the only protein that participates in binding of fibronectin by $Y$. pestis (Tsang et al., 2010). These interactions are responsible for $Y$. pestis attachment to host cells (see above in section "Role of Ail in adhesiveness of $Y$. pestis mammalian cells"). Structural and adhesion (employing purified Ail and Ail-expressing E. coli) studies, show that Ail specifically binds a $40 \mathrm{kDA}$ laminin fragment called LG4-5 (Laminin G-like domains 4 and 5) although other laminin domains can also facilitate the adhesion process (Yamashita et al., 2011). Recent studies by Tsang et al. identified that Ail mediates bacterial binding to the centrally located $120 \mathrm{kDA}$ fragment of fibronectin, more precisely to ${ }^{9}$ FNIII module neighboring the RGD site present in ${ }^{10}$ FNIII region (Tsang et al., 2012).

Disruption of Ail interaction with both laminin (Yamashita et al., 2011) and fibronectin (Tsang et al., 2010; Yamashita et al., 2011) alleviate Yop delivery into mammalian cells. Even though Ail interaction with laminin is stronger than with fibronectin 
in the abiotic models (protein coated glass), it is the binding to fibronectin that contributes to increased Yop delivery into the host cells (HEp-2). The pretreatment of the host cells with antilaminin antibodies itself does not inhibit Yop delivery; however, a combination of both antibodies, anti-fibronectin, and antilaminin have a synergistic effect and significantly decreases cytotoxicity compared to treatment with anti-fibronectin antibody alone (Yamashita et al., 2011).

It was also suggested that Ail-mediated interaction of $Y$. pestis with epithelial cells involve heparin sulfate proteoglycan (Zhang et al., 2008). X-ray diffraction crystal structure studies revealed two binding sites for sucrose octasulfate (SOS), a smaller heparin analog, that corresponds to two positively charged sites found on the Ail molecule (Yamashita et al., 2011), designated HBS-I and HBS-II (heparin-binding site 1 and 2, respectively). The HBS-I is the primary binding site for SOS and is located on the extracellular surface on the outside of the $\beta$-barrel. Extracellular loops 2 and 3 contribute residues to form HBS-I while extracellular loop 1 contributes to form HBS-II. Mutations in these regions show weak binding to heparin (Yamashita et al., 2011). No studies on the role of Ail-HPSG interactions and delivery of Yop have been done.

\section{ROLE OF AIL IN INVASIVENESS OF $Y$. pestis INTO NON-PROFESSIONAL PHAGOCYTIC CELLS}

Bacterial invasiveness is another mechanism to circumvent host immune response (Hess et al., 2001). Y. pestis is a facultative intracellular pathogen that resides both inside and outside of the host cells during infection (Perry and Fetherston, 1997). Although macrophages and dendritic cells are the target host cells for Y. pestis (Marketon et al., 2005), internalization into non-professional phagocytes occurs (Cowan et al., 2000). Work by Cowan et al. found that $Y$. pestis is highly invasive in HeLa cells when grown at 26 , but not at $37^{\circ} \mathrm{C}$ (Cowan et al., 2000). Deletion of Ail results in impaired internalization of Y. pestis ( $\sim 60$-fold decrease) by human epithelial cells (HEp-2) (Kolodziejek et al., 2007), although the invasive properties of y1324 were not confirmed by Felek et al. (Felek and Krukonis, 2009). When expressed in E. coli, Ail confers internalization independently from other $Y$. pestis proteins or LPS, but the efficiency of internalization depends on the LPS core background in which the protein is expressed. Progressive truncation of LPS core results in progressive decrease in Ail-conferred internalization of E. coli (Figure 3C). The most pronounced effect is seen with the Ail-expressing deep rough strain that can readily attach to the epithelial cells, but cannot invade them (Kolodziejek et al., 2010).

$Y$. pestis Ail shares functional homology in invasiveness with Ail from Y. enterocolitica (Miller and Falkow, 1988) but not with Ail from Y. pseudotuberculosis (Yang et al., 1996) (for discussion of the functional discrepancies see "Role of Ail in Y. pestis adhesion to mammalian cells"). In contrast to enteropathogenic Yersiniae that posses in their repertoire other proteins involved in cellular uptake (invasin and YadA) (Isberg et al., 1987; Eitel and Dersch, 2002), ail is the only gene that is both common within the genus and shown to be involved in internalization of $Y$. pestis (while the Pla protease-encoding plasmid pPCP1 was shown to mediate Y. pestis internalization (Cowan et al., 2000), it is not present in other Yersiniae). YadA structural homolog, YadBC was found to be moderately involved in $Y$. pestis uptake, but its role in $Y$. pseudotuberculosis is not known and the gene is not present in Y. enterocolitica (Forman et al., 2008).

\section{AIL AND AUTOAGGREGATION OF $Y$. pestis}

The autoaggregation phenotype is often attributed to biofilm formation on abiotic and biotic surfaces in many bacteria and is associated with circumvention of the host defense mechanisms during infection. The autoaggregation phenotype expressed by pellicle formation at the air-liquid interface and by flocculent growth is characteristic for $Y$. pestis and is connected to virulence (Laird and Cavanaugh, 1980; Kolodziejek et al., 2010). It can be observed at 28 and $37^{\circ} \mathrm{C}$ (Kolodziejek et al., 2007), but not at $6^{\circ} \mathrm{C}$ (author's observation) which correlates nicely with the pattern of Ail expression (Bartra et al., 2008). Indeed, deletion of Ail confers loss of these characteristics when the bacterium is grown in LB medium (Kolodziejek et al., 2007). Ail-induced autoaggregation does not contribute to serum resistance (by making the bacterial cells inaccessible to complement components), but it is critical for effective bacterial adherence (Kolodziejek et al., 2007, 2010). Y. pestis ail-negative mutants that have lost the autoaggregation phenotype and E. coli expressing Ail, but showing no flocculent growth, have impaired ability to adhere to epithelial cells (Kolodziejek et al., 2010). Also, the Ail-conferred autoaggregation seems to depend on the display of the protein in a specific LPS core background. A series of Ail-expressing E. coli with progressively truncated LPS differ in flocculent growth and pellicle formation (Figure 3) (Kolodziejek et al., 2010).

\section{Y. pestis AIL IS A VIRULENCE FACTOR}

Although Ail in Y. enterocolitica is present in all pathogenic strains (Miller et al., 1989b), no changes in virulence are observed when the gene is deleted (Wachtel and Miller, 1995). No information regarding the role of Ail in Y. pseudotuberculosis virulence is available. In contrast, Ail in Y. pestis is a required virulence factor. Full assessment of Ail's role in $Y$. pestis pathogenesis requires use of multiple animal models. Because murine serum is not bactericidal for ail-negative $Y$. pestis, experiments with mice cannot fully assess the role of serum resistance in plague pathogenesis and studies in mice mostly reflect the role of adhesive/invasive phenotype of Ail. Rats make a better model of $Y$. pestis pathogenesis since their serum is similar to humans in that it is bactericidal to the ail mutant. Comparison of the mortality between the mice and rats following $Y$. pestis challenge (see below) indicates that serum resistance contributes to virulence more prominently than bacterial association with the host cells. Other models, employing Caenorhabditis elegans and fleas, have investigated the role of Ail in virulence and flea transmission.

\section{RAT MODEL OF PLAGUE}

Ail is an essential virulence factor in the pneumonic (intranasal infection) and bubonic (intradermal injection) model of plague in rats (Kolodziejek et al., 2010; Hinnebusch et al., 2011). Deletion of Ail completely attenuates virulence of $Y$. pestis CO92 in pneumonic model of infection; all rats challenged with the highest dose of $1 \times 10^{8} \mathrm{CFU}$ survive, vs. the $\mathrm{LD}_{50}$ of $1.2 \times 10^{3} \mathrm{CFU}$ 
established for the wild-type strain (Kolodziejek et al., 2010). Similarly, in a bubonic model of plague infection with up to $3 \times 10^{4} \mathrm{CFU}$ of the $Y$. pestis CO92 ail-negative strain produce no mortality and no signs of systemic plague morbidity, and most of the animals have no $Y$. pestis cultured from their spleens 17-20 days after the infection (Hinnebusch et al., 2011). These observations are in contrast with animals infected with the wild-type strain: a very small $\mathrm{LD}_{50}$ dose (Table 1) leads to death of the animals within 2-5 days post injection. The presence of high wildtype bacterial numbers in the spleen in late stages of infection coupled with systemic signs of terminal disease likewise contrasts with the infection pattern of ail mutant. Interestingly, even though the animals infected with the ail mutant do not show other signs of morbidity (the animals remain alert and active) they present enlarged lymph nodes that develop during the second week post infection. The purulent lymphadenitis is never observed in the rats infected with the wild-type in which the buboes are characterized with (1) massive accumulation of bacteria within 3-5 days, (2) a hemorrhage, and (3) no signs of pus or strong PMNL response. Meanwhile, ail-negative strain develops buboes with the pronounced number of PMNLs; (1) large abscesses encapsulating PMNLs and bacteria, (2) sterile and resolving abscess's with PMNLs, fibroblasts, macrophages, and multinucleated giant cells, and (3) immunoglobulin-producing plasma cells. All these features are evidence of the chronic inflammatory response induced by infections with the ail mutant that is not seen with the wild-type (Hinnebusch et al., 2011).

\section{MOUSE MODEL OF PLAGUE}

In mouse models of pneumonic plague, deletion of Ail in Y. pestis CO92 extends the time-to-death, but does not alter the $\mathrm{LD}_{50}$ value (Table 1). Overall, deletion of Ail delays 100\% mortality rate by $24-48 \mathrm{~h}$ depending on the challenge dose (10 LD 50 and $100 \mathrm{LD}_{50}$, respectively) (Kolodziejek et al., 2010). In contrast, intradermal and intravenous (tail vein) infection with ail mutants (in Y. pestis CO92 and Y. pestis KIM5, respectively) attenuates both strains and results in $\sim 10^{3}$-fold increase in $\mathrm{LD}_{50}$ value (Table 1) (Felek and Krukonis, 2009; Hinnebusch et al., 2011). The same KIM5 ail-negative strain inoculated via retroorbital route has no defect in virulence (Bartra et al., 2008). The histopathological changes specific for mice infected with the ail mutant include: (1) enlarged lymph nodes containing abscesses and some puss (bubonic model) (Hinnebusch et al., 2011); (2) increase in immune cell infiltration in spleen and liver tissues, their damage, and spleen enlargement (septicemic model) (Felek and Krukonis, 2009). Additionally, different kinetics of bacterial colonization are found for the ail-negative strain in the intravenous infection model. At the beginning of infection both mutant and wild-type strains colonizes spleen, liver, and lung tissue similarly, but as the infection progresses, the number of the ail mutant bacteria retrieved from the tissues dramatically decline (Felek and Krukonis, 2009).

\section{Caenorhabditis elegans AND A FLEA MODEL OF Y. pestis INFECTION}

Ail is required for biofilm-independent killing of Caenorhabditis elegans (Bartra et al., 2008) as its deletion increases survival of adult worms infected with Y. pestis KIM5. However, even though deletion of ail changes the autoaggregation phenotype in $Y$. pestis, it does not affect biofilm-dependent killing of the nematode (Bartra et al., 2008). Similarly, deletion of ail does not alter either the infection rate or bacterial blockage of the flea (X. cheopsis) necessary for effective plague transmission from a vector to a mammalian host (Bartra et al., 2008).

\section{AIL AS A POTENTIAL VACCINE CANDIDATE AGAINST $Y$. pestis HUMAN INFECTIONS}

Presently, there is no effective plague vaccine (Williamson, 2009). Killed whole cells vaccines (known since late 1890's) and a live attenuated Y. pestis EV76 strain decrease the incidence but do not provide long-lasting efficacious protection against bubonic plague and provide no protection against the pneumonic form of the disease. Additionally, severe side-effects can occur after vaccination. Therefore, the use of the killed whole cells vaccine was discontinued in the United States in 1998 and at present no vaccine is available (Butler, 2009). With the biological threat and appearance of drug resistant strains of $Y$. pestis, there have been increased efforts to develop more effective vaccines to ensure full protection especially against the aerosol-borne form of the disease (Williamson, 2001, 2009). The surface-exposed localization of Ail, the robust induction of inflammatory response in lymphoid tissues caused by ail-negative strain, and Ail's overall pronounced role in virulence of this notorious pathogen make the protein a good potential vaccine target. It has already been shown that rats subcutaneously infected with the ail mutant have very high serum antibody titers against Caf1 protein, indicative of a strong protective response against $Y$. pestis. Moreover, the persistent infection in the lymph nodes uniquely generated by ail mutant in rats, and not by other $Y$. pestis attenuated strains due to their rapid clearance, can serve as an important tool in identifying key players of $Y$. pestis infection and the potential elucidation of new vaccine targets (Hinnebusch et al., 2011).

\section{CONCLUDING REMARKS}

The elements of $Y$. pestis pathogenesis are still being elucidated. This review describes the current understanding of the role of Ail protein in the course of infection. The explanations behind its pronounced role are provided; (1) inhibition of bactericidal properties of the complement, (2) attachment and Yop delivery to host tissue, (3) prevention of PMNL recruitment to the lymph nodes, (4) inhibition of inflammatory response (Kolodziejek et al., 2007; Felek and Krukonis, 2009; Hinnebusch et al., 2011) are the crucial phenotypes mediated by Ail. Also, some comparison to Ail phenotype in Y. enterocolitica and Y. pseudotuberculosis is made to illustrate differences that could potentially contributed to the drastic change of the bacterial lifestyle that resulted in a shift from an entero- to a vector-borne systemic pathogen.

\section{ACKNOWLEDGMENTS}

This work was supported by the National Institutes of Health (grants P20 RR15587, P20 RR016454, P20 GM103408 and U54AI57141) and the Idaho Agricultural Experimental Station. 


\section{REFERENCES}

Achtman, M., Morelli, G., Zhu, P., Wirth, T., Diehl, I., Kusecek, B., Vogler, A. J., Wagner, D. M., Allender, C. J., Easterday, W. R., Chenal-Francisque, V., Worsham, P., Thomson, N. R., Parkhill, J., Lindler, L. E., Carniel, E., and Keim, P. (2004). Microevolution and history of the plague bacillus, Yersinia pestis. Proc. Natl. Acad. Sci. U.S.A. 101, 17837-17842.

Achtman, M., Zurth, K., Morelli, G., Torrea, G., Guiyoule, A., and Carniel, E. (1999). Yersinia pestis, the cause of plague, is a recently emerged clone of Yersinia pseudotuberculosis. Proc. Natl. Acad. Sci. U.S.A. 96, 14043-14048.

Airhart, C. L., Rohde, H. N., Bohach, G. A., Hovde, C. J., Deobald, C. F., Lee, S. S., and Minnich, S. A. (2008). Induction of innate immunity by lipid A mimetics increases survival from pneumonic plague. Microbiology 154, 2131-2138.

Anisimov, A. P., Dentovskaya, S. V., Titareva, G. M., Bakhteeva, I. V., Shaikhutdinova, R. Z., Balakhonov, S. V., Lindner, B., Kocharova, N. A., Senchenkova, S. N., Holst, O., Pier, G. B., and Knirel, Y. A. (2005). Intraspecies and temperature-dependent variations in susceptibility of Yersinia pestis to the bactericidal action of serum and to polymyxin B. Infect. Immun. 73, 7324-7331.

Anisimov, A. P., Lindler, L. E., and Pier, G. B. (2004). Intraspecific diversity of Yersinia pestis. Clin. Microbiol. Rev. 17, 434-464.

Bartra, S. S., Styer, K. L., O’bryant, D. M., Nilles, M. L., Hinnebusch, B. J., Aballay, A., and Plano, G. V. (2008). Resistance of Yersinia pestis to complement-dependent killing is mediated by the Ail outer membrane protein. Infect. Immun. 76, 612-622.

Ben-Gurion, R., and Shafferman, A. (1981). Essential virulence determinants of different Yersinia species are carried on a common plasmid. Plasmid 5, 183-187.

Bercovier, H., Mollaret, H. H., Alonso, J. M., Brault, J., Fanning, G. R., Steigerwalt, A. G., and Brenner, D. J. (1980). Intra- and interspecies relatedness of Yersinia pestis by DNA hybridization and its relationship toYersinia pseudotuberculosis. Curr. Microbiol. 4, 225-229.

Biedzka-Sarek, M., Jarva, H., Hyytiainen, H., Meri, S., and Skurnik, M. (2008a). Characterization of complement factor $\mathrm{H}$ binding to Yersinia enterocolitica serotype O:3. Infect. Immun. 76, 4100-4109.

Biedzka-Sarek, M., Salmenlinna, S., Gruber, M., Lupas, A. N., Meri, S., and Skurnik, M. (2008b). Functional mapping of YadA- and Ail-mediated binding of human factor $\mathrm{H}$ to Yersinia enterocolitica serotype O:3. Infect. Immun. 76, 5016-5027.

Biedzka-Sarek, M., Venho, R., and Skurnik, M. (2005). Role of YadA, Ail, and lipopolysaccharide in serum resistance of Yersinia enterocolitica serotype O:3. Infect. Immun. 73, 2232-2244.

Bliska, J. B., and Falkow, S. (1992). Bacterial resistance to complement killing mediated by the Ail protein of Yersinia enterocolitica. Proc. Natl. Acad. Sci. U.S.A. 89, 3561-3565.

Butler, T. (2009). Plague into the 21st century. Clin. Infect. Dis. 49, 736-742.

Chain, P. S., Carniel, E., Larimer, F. W., Lamerdin, J., Stoutland, P. O., Regala, W. M., Georgescu, A. M., Vergez, L. M., Land, M. L., Motin, V. L., Brubaker, R. R., Fowler, J., Hinnebusch, J., Marceau, M., Medigue, C., Simonet, M., ChenalFrancisque, V., Souza, B., Dacheux, D., Elliott, J. M., Derbise, A., Hauser, L. J., and Garcia, E. (2004). Insights into the evolution of Yersinia pestis through whole-genome comparison with Yersinia pseudotuberculosis. Proc. Natl. Acad. Sci. U.S.A. 101, 13826-13831.

Chain, P. S., Hu, P., Malfatti, S. A., Radnedge, L., Larimer, F., Vergez, L. M., Worsham, P., Chu, M. C., and Andersen, G. L. (2006). Complete genome sequence of Yersinia pestis strains Antiqua and Nepal516, evidence of gene reduction in an emerging pathogen. J. Bacteriol. 188, 4453-4463.

Chauvaux, S., Dillies, M. A., Marceau, M., Rosso, M. L., Rousseau, S., Moszer, I., Simonet, M., and Carniel, E. (2011). In silico comparison of Yersinia pestis and Yersinia pseudotuberculosis transcriptomes reveals a higher expression level of crucial virulence determinants in the plague bacillus. Int. J. Med. Microbiol. 301, 105-116.

Chauvaux, S., Rosso, M. L., Frangeul, L., Lacroix, C., Labarre, L., Schiavo, A., Marceau, M., Dillies, M. A., Foulon, J., Coppee, J. Y., Medigue, C., Simonet, M., and Carniel, E. (2007). Transcriptome analysis of Yersinia pestis in human plasma: an approach for discovering bacterial genes involved in septicaemic plague. Microbiology 153, 3112-3124.
Cirillo, D. M., Heffernan, E. J., Wu, L., Harwood, J., Fierer, J., and Guiney, D. G. (1996). Identification of a domain in Rck, a product of the Salmonella typhimurium virulence plasmid, required for both serum resistance and cell invasion. Infect. Immun. 64, 2019-2023.

Cowan, C., Jones, H. A., Kaya, Y. H., Perry, R. D., and Straley, S. C. (2000). Invasion of epithelial cells by Yersinia pestis: evidence for a $Y$. pestis-specific invasin. Infect. Immun. 68, 4523-4530.

Darby, C., Ananth, S. L., Tan, L., and Hinnebusch, B. J. (2005). Identification of $g m h A$, a Yersinia pestis gene required for flea blockage, by using a Caenorhabditis elegans biofilm system. Infect. Immun. 73, 7236-7242.

Dentovskaya, S. V., Anisimov, A. P., Kondakova, A. N., Lindner, B. Bystrova, O. V., Svetoch, T. E., Shaikhutdinova, R. Z., Ivanov, S. A., Bakhteeva, I. V., Titareva, G. M., and Knirel, A. Y. (2011). Functional characterization and biological significance of Yersinia pestis lipopolysaccharide biosynthesis genes. Biochemistry (Mosc.) 76, 808-822.

Derbise, A., Chenal-Francisque, V., Pouillot, F., Fayolle, C., Prevost, M. C., Medigue, C., Hinnebusch, B. J., and Carniel, E. (2007). A horizontally acquired filamentous phage contributes to the pathogenicity of the plague bacillus. Mol. Microbiol. 63, 1145-1157.

Eitel, J., and Dersch, P. (2002). The YadA protein of Yersinia pseudotuberculosis mediates high-efficiency uptake into human cells under environmental conditions in which invasin is repressed. Infect. Immun. 70, 4880-4891.

Eppinger, M., Rosovitz, M. J., Fricke, W. F., Rasko, D. A., Kokorina, G. Fayolle, C., Lindler, L. E., Carniel, E., and Ravel, J. (2007). The complete genome sequence of Yersinia pseudotuberculosis IP31758, the causative agent of Far East scarletlike fever. PLoS Genet. 3:e142. doi: 10.1371/journal.pgen.0030142

Erickson, D. L., Jarrett, C. O., Callison, J. A., Fischer, E. R. and Hinnebusch, B. J. (2008). Loss of a biofilm-inhibiting glycosyl hydrolase during the emergence of Yersinia pestis. J. Bacteriol. 190, 8163-8170.

Erickson, D. L., Jarrett, C. O., Wren, B. W., and Hinnebusch, B. J. (2006). Serotype differences and lack of biofilm formation characterize Yersinia pseudotuberculosis infection of the Xenopsylla cheopis flea vector of Yersinia pestis. J. Bacteriol. 188, 1113-1119.

Eroshenko, G. A., Odinokov, G. N., Kukleva, L. M., Krasnov Ia, M., and Kutyrev, V. V. (2010). Sequence analysis of the yadA, inv, and ail genes and their expression in the main and nonmain Yersinia pestis subspecies and Yersinia pseudotuberculosis. Genetika 46, 734-741.

Felek, S., and Krukonis, E. S. (2009). The Yersinia pestis Ail protein mediates binding and Yop delivery to host cells required for plague virulence. Infect. Immun. 77, 825-836.

Felek, S., Tsang, T. M., and Krukonis, E. S. (2010). Three Yersinia pestis adhesins facilitate Yop delivery to eukaryotic cells and contribute to plague virulence. Infect. Immun. 78, 4134-4150.

Forman, S., Wulff, C. R., MyersMorales, T., Cowan, C., Perry, R. D., and Straley, S. C. (2008). yadBC of Yersinia pestis, a new virulence determinant for bubonic plague. Infect. Immun. 76, 578-587.

Galindo, C. L., Sha, J., Moen, S. T., Agar, S. L., Kirtley, M. L., Foltz, S. M., McIver, L. J., Kozlova, E. V., Garner, H. R., and Chopra, A. K. (2010). Comparative global gene expression profiles of wild-type Yersinia pestis CO92 and its braun lipoprotein mutant at flea and human body temperatures. Comp. Funct. Genomics 2010, 342168.

Heffernan, E. J., Harwood, J., Fierer, J., and Guiney, D. (1992). The Salmonella typhimurium virulence plasmid complement resistance gene rck is homologous to a family of virulence-related outer membrane protein genes, including pagC and ail. J. Bacteriol. 174, 84-91.

Heise, T., and Dersch, P. (2006). Identification of a domain in Yersinia virulence factor YadA that is crucial for extracellular matrixspecific cell adhesion and uptake. Proc. Natl. Acad. Sci. U.S.A. 103, 3375-3380.

Hess, D. J., Henry-Stanley, M. J., Moore, E. A., and Wells, C. L. (2001) Integrin expression, enterocyte maturation, and bacterial internalization. J. Surg. Res. 98, 116-122.

Hinnebusch, B. J., and Erickson, D. L. (2008). Yersinia pestis biofilm in the flea vector and its role in the transmission of plague. Curr. Top. Microbiol. Immunol. 322, 229-248.

Hinnebusch, B. J., Jarrett, C. O., Callison, J. A., Gardner, D., Buchanan, S. K., and Plano, G. V. (2011). Role of the Yersinia pestis Ail protein in preventing a protective polymorphonuclear leukocyte 
response during bubonic plague. Infect. Immun. 79, 4984-4989.

Hixson, K. K., Adkins, J. N., Baker, S. E., Moore, R. J., Chromy, B. A., Smith, R. D., McCutchen-Maloney, S. L., and Lipton, M. S. (2006). Biomarker candidate identification in Yersinia pestis using organism-wide semiquantitative proteomics. J. Proteome Res. 5, 3008-3017.

Ho, D. K., Riva, R., Kirjavainen, V., Jarva, H., Ginstrom, E., Blom, A. M., Skurnik, M., and Meri, S. (2012). Functional recruitment of the human complement inhibitor C4BP to Yersinia pseudotuberculosis outer membrane protein Ail. J. Immunol. 188, 4450-4459.

Isberg, R. R., Voorhis, D. L., and Falkow, S. (1987). Identification of invasin: a protein that allows enteric bacteria to penetrate cultured mammalian cells. Cell 50, 769-778.

Junkes, C., Wessolowski, A., Farnaud, S., Evans, R. W., Good, L., Bienert, M., and Dathe, M. (2008). The interaction of arginine- and tryptophan-rich cyclic hexapeptides with Escherichia coli membranes. J. Pept. Sci. 14, 535-543.

Kirjavainen, V., Jarva, H., BiedzkaSarek, M., Blom, A. M., Skurnik, M., and Meri, S. (2008). Yersinia enterocolitica serum resistance proteins YadA and ail bind the complement regulator $\mathrm{C} 4 \mathrm{~b}$-binding protein. PLoS Pathog. 4:e1000140. doi: 10.1371/journal.ppat.1000140

Knirel, Y. A., Dentovskaya, S. V., Bystrova, O. V., Kocharova, N. A., Senchenkova, S. N., Shaikhutdinova, R. Z., Titareva, G. M., Bakhteeva, I. V., Lindner, B., Pier, G. B., and Anisimov, A. P. (2007). Relationship of the lipopolysaccharide structure of Yersinia pestis to resistance to antimicrobial factors. $A d v$. Exp. Med. Biol. 603, 88-96.

Knirel, Y. A., Dentovskaya, S. V., Senchenkova, S. N., Shaikhutdinova, R. Z., Kocharova, N. A., and Anisimov, A. P. (2006). Structural features and structural variability of the lipopolysaccharide of Yersinia pestis, the cause of plague. J. Endotoxin Res. 12, 3-9.

Kolodziejek, A. M., Schnider, D. R., Rohde, H. N., Wojtowicz, A. J., Bohach, G. A., Minnich, S. A., and Hovde, C. J. (2010). Outer membrane protein X (Ail) contributes to Yersinia pestis virulence in pneumonic plague and its activity is dependent on the lipopolysaccharide core length. Infect. Immun. 78, 5233-5243.

Kolodziejek, A. M., Sinclair, D. J., Seo, K. S., Schnider, D. R., Deobald,
C. F., Rohde, H. N., Viall, A. K., Minnich, S. S., Hovde, C. J., Minnich, S. A., and Bohach, G. A. (2007). Phenotypic characterization of OmpX, an Ail homologue of Yersinia pestis KIM. Microbiology 153, 2941-2951.

Laird, W. J., and Cavanaugh, D. C. (1980). Correlation of autoagglutination and virulence of yersiniae. J. Clin. Microbiol. 11, 430-432.

Lathem, W. W., Price, P. A., Miller, V. L., and Goldman, W. E. (2007). A plasminogen-activating protease specifically controls the development of primary pneumonic plague. Science 315, 509-513.

Lawrenz, M. B., Lenz, J. D., and Miller, V. L. (2009). A novel autotransporter adhesin is required for efficient colonization during bubonic plague. Infect. Immun. 77, 317-326.

Liu, F., Chen, H., Galvan, E. M., Lasaro, M. A., and Schifferli, D. M. (2006). Effects of Psa and F1 on the adhesive and invasive interactions of Yersinia pestis with human respiratory tract epithelial cells. Infect. Immun. 74, 5636-5644.

Marcus, S., Esplin, D. W., and Donaldson, D. M. (1954). Lack of bactericidal effect of mouse serum on a number of common microorganisms. Science 119, 877.

Marketon, M. M., Depaolo, R. W., Debord, K. L., Jabri, B., and Schneewind, O. (2005). Plague bacteria target immune cells during infection. Science 309, 1739-1741.

Miller, S. I., Kukral, A. M., and Mekalanos, J. J. (1989a). A twocomponent regulatory system (phoP phoQ) controls Salmonella typhimurium virulence. Proc. Natl. Acad. Sci. U.S.A. 86, 5054-5058.

Miller, V. L., Farmer, J. J. 3rd., Hill, W. E., and Falkow, S. (1989b). The ail locus is found uniquely in Yersinia enterocolitica serotypes commonly associated with disease. Infect. Immun. 57, 121-131.

Miller, V. L., and Falkow, S. (1988). Evidence for two genetic loci in Yersinia enterocolitica that can promote invasion of epithelial cells. Infect. Immun. 56, 1242-1248.

Montminy, S. W., Khan, N., McGrath, S., Walkowicz, M. J., Sharp, F., Conlon, J. E., Fukase, K., Kusumoto, S., Sweet, C., Miyake, K., Akira, S., Cotter, R. J., Goguen, J. D., and Lien, E. (2006). Virulence factors of Yersinia pestis are overcome by a strong lipopolysaccharide response. Nat. Immunol. 7, 1066-1073.

Moran, N. A. (2002). Microbial minimalism: genome reduction in bacterial pathogens. Cell 108, 583-586.
Myers-Morales, T., Cowan, C., Gray, M. E., Wulff, C. R., Parker, C. E., Borchers, C. H., and Straley, S. C. (2007). A surface-focused biotinylation procedure identifies the Yersinia pestis catalase KatY as a membrane-associated but non-surface-located protein. Appl. Environ. Microbiol. 73, 5750-5759.

Nikaido, H., and Vaara, M. (1985). Molecular basis of bacterial outer membrane permeability. Microbiol. Rev. 49, 1-32.

Parkhill, J., Wren, B. W., Thomson, N R., Titball, R. W., Holden, M. T., Prentice, M. B., Sebaihia, M., James, K. D., Churcher, C., Mungall, K. L., Baker, S., Basham, D., Bentley, S. D., Brooks, K., Cerdeno-Tarraga, A. M., Chillingworth, T., Cronin, A. Davies, R. M., Davis, P., Dougan, G., Feltwell, T., Hamlin, N., Holroyd, S., Jagels, K., Karlyshev, A. V., Leather, S., Moule, S., Oyston, P. C., Quail, M., Rutherford, K., Simmonds, M., Skelton, J., Stevens, K., Whitehead, S., and Barrell, B. G. (2001). Genome sequence of Yersinia pestis, the causative agent of plague. Nature 413, 523-527.

Perry, R. D., and Fetherston, J. D. (1997). Yersinia pestis-etiologic agent of plague. Clin. Microbiol. Rev. 10, 35-66.

Pieper, R., Huang, S. T., Clark, D. J., Robinson, J. M., Alami, H., Parmar, P. P., Suh, M. J., Kuntumalla, S., Bunai, C. L., Perry, R. D., Fleischmann, R. D., and Peterson, S. N. (2009a). Integral and peripheral association of proteins and protein complexes with Yersinia pestis inner and outer membranes. Proteome Sci. 7,5 .

Pieper, R., Huang, S. T., Robinson, J. M., Clark, D. J., Alami, H., Parmar, P. P., Perry, R. D., Fleischmann, R. D., and Peterson, S. N. (2009b). Temperature and growth phase influence the outer-membrane proteome and the expression of a type VI secretion system in Yersinia pestis. Microbiology 155, 498-512.

Pierson, D. E., and Falkow, S. (1993). The ail gene of Yersinia enterocolitica has a role in the ability of the organism to survive serum killing. Infect. Immun. 61, 1846-1852.

Plesniak, L. A., Mahalakshmi, R., Rypien, C., Yang, Y., Racic, J., and Marassi, F. M. (2011). Expression, refolding, and initial structural characterization of the Y. pestis Ail outer membrane protein in lipids. Biochim. Biophys. Acta 1808, 482-489.

Prior, J. L., Parkhill, J., Hitchen, P. G., Mungall, K. L., Stevens, K., Morris, H. R., Reason, A. J., Oyston, P. C.,
Dell, A., Wren, B. W., and Titball, R. W. (2001). The failure of different strains of Yersinia pestis to produce lipopolysaccharide $\mathrm{O}$-antigen under different growth conditions is due to mutations in the $\mathrm{O}$-antigen gene cluster. FEMS Microbiol. Lett. 197, 229-233.

Prokhorenko, I. R., Zubova, S. V., Ivanov, A. Y., and Grachev, S. V. (2009). Interaction of Gramnegative bacteria with cationic proteins: dependence on the surface characteristics of the bacterial cell. Int. J. Gen. Med. 2, 33-38.

Razatos, A., Ong, Y. L., Sharma, M. M., and Georgiou, G. (1998). Molecular determinants of bacterial adhesion monitored by atomic force microscopy. Proc. Natl. Acad. Sci. U.S.A. 95, 11059-11064.

Reid, G., and Sobel, J. D. (1987) Bacterial adherence in the pathogenesis of urinary tract infection: a review. Rev. Infect. Dis. 9, 470-487.

Rosqvist, R., Skurnik, M., and WolfWatz, H. (1988). Increased virulence of Yersinia pseudotuberculosis by two independent mutations. Nature 334, 522-524.

Sebbane, F., Jarrett, C., Gardner, D., Long, D., and Hinnebusch, B. J. (2009). The Yersinia pestis caf1M1A1 fimbrial capsule operon promotes transmission by flea bite in a mouse model of bubonic plague. Infect. Immun. 77, 1222-1229.

Sebbane, F., Jarrett, C. O., Gardner, D., Long, D., and Hinnebusch, B. J. (2006). Role of the Yersinia pestis plasminogen activator in the incidence of distinct septicemic and bubonic forms of flea-borne plague. Proc. Natl. Acad. Sci. U.S.A. 103, 5526-5530.

Simonet, M., Riot, B., Fortineau, N., and Berche, P. (1996). Invasin production by Yersinia pestis is abolished by insertion of an IS200-like element within the inv gene. Infect. Immun. 64, 375-379.

Skurnik, M., Peippo, A., and Ervela, E. (2000). Characterization of the $\mathrm{O}$-antigen gene clusters of Yersinia pseudotuberculosis and the cryptic $\mathrm{O}$-antigen gene cluster of Yersinia pestis shows that the plague bacillus is most closely related to and has evolved from Y. pseudotuberculosis serotype O:1b. Mol. Microbiol. 37, 316-330.

Sun, Y. C., Hinnebusch, B. J., and Darby, C. (2008). Experimental evidence for negative selection in the evolution of a Yersinia pestis pseudogene. Proc. Natl. Acad. Sci. U.S.A. 105, 8097-8101. 
Tedesco, F. (2008). Inherited complement deficiencies and bacterial infections. Vaccine 26(Suppl. 8), I3-I8.

Tsang, T. M., Annis, D. S., Kronshage, M., Fenno, J. T., Usselman, L. D., Mosher, D. F., and Krukonis, E. S. (2012). Ail binds 9FNIII within the central $120-\mathrm{kD}$ a region of fibronectin to facilitate cell binding by Yersinia pestis. J. Biol. Chem. 287, 16759-16767.

Tsang, T. M., Felek, S., and Krukonis, E. S. (2010). Ail binding to fibronectin facilitates Yersinia pestis binding to host cells and Yop delivery. Infect. Immun. 78, 3358-3368.

Une, T., and Brubaker, R. R. (1984). In vivo comparison of avirulent Vwa- and Pgm- or Pstr phenotypes of yersiniae. Infect. Immun. 43, 895-900.

Wachtel, M. R., and Miller, V. L. (1995). In vitro and in vivo characterization of an ail mutant of Yersinia enterocolitica. Infect. Immun. 63, 2541-2548.
Wachter, E., and Brade, V. (1989). Influence of surface modulations by enzymes and monoclonal antibodies on alternative complement pathway activation by Yersinia enterocolitica. Infect. Immun. 57, 1984-1989.

Welkos, S. L., Friedlander, A. M., and Davis, K. J. (1997). Studies on the role of plasminogen activator in systemic infection by virulent Yersinia pestis strain C092. Microb. Pathog. 23, 211-223.

Williamson, E. D. (2001). Plague vaccine research and development. J. Appl. Microbiol. 91, 606-608.

Williamson, E. D. (2009). Plague. Vaccine 27(Suppl. 4), D56-D60.

Wimsatt, J., and Biggins, D. E. (2009). A review of plague persistence with special emphasis on fleas. J. Vector Borne Dis. 46, 85-99.

Yamashita, S., Lukacik, P., Barnard, T. J., Noinaj, N., Felek, S., Tsang, T. M., Krukonis, E. S., Hinnebusch, B. J., and Buchanan, S. K. (2011).
Structural insights into Ailmediated adhesion in Yersinia pestis. Structure 19, 1672-1682.

Yang, Y., Merriam, J. J., Mueller, J. P., and Isberg, R. R. (1996). The $p s a$ locus is responsible for thermoinducible binding of Yersinia pseudotuberculosis to cultured cells. Infect. Immun. 64, 2483-2489.

Yu, F., and Mizushima, S. (1982). Roles of lipopolysaccharide and outer membrane protein OmpC of Escherichia coli $\mathrm{K}-12$ in the receptor function for bacteriophage T4. J. Bacteriol. 151, 718-722.

Zhang, P., Skurnik, M., Zhang, S. S., Schwartz, O., Kalyanasundaram, R., Bulgheresi, S., He, J. J., Klena, J. D., Hinnebusch, B. J., and Chen, T. (2008). Human dendritic cellspecific intercellular adhesion molecule-grabbing nonintegrin (CD209) is a receptor for Yersinia pestis that promotes phagocytosis by dendritic cells. Infect. Immun. 76, 2070-2079.

Conflict of Interest Statement: The authors declare that the research was conducted in the absence of any commercial or financial relationships that could be construed as a potential conflict of interest.

Received: 17 May 2012; accepted: 14 July 2012; published online: 06 August 2012. Citation: Kolodziejek AM, Hovde CJ and Minnich SA (2012) Yersinia pestis Ail: multiple roles of a single protein. Front. Cell. Inf. Microbio. 2:103. doi: 10.3389/ fcimb.2012.00103

Copyright (C) 2012 Kolodziejek, Hovde and Minnich. This is an open-access article distributed under the terms of the Creative Commons Attribution License, which permits use, distribution and reproduction in other forums, provided the original authors and source are credited and subject to any copyright notices concerning any third-party graphics etc. 